\title{
Ecogeographical variations of the vegetative and floral traits of Lilium amabile Palibian
}

\author{
Viet Yen Nguyen $\cdot$ Rameshwar Rai $\cdot$ Jong-Hwa Kim $\cdot$ Ji-Young Kim $\cdot$ Jong-Kuk Na
}

Received: 6 November 2021 / Revised: 13 December 2021 / Accepted: 13 December 2021

(C) Korean Society for Plant Biotechnology

\begin{abstract}
This study aimed to characterize the morphological variations in the vegetative and floral traits of 73 wild Lilium amabile plants from six habitats in Korea. It was observed that $L$. amabile is distributed nationwide at any altitude from $300 \mathrm{~m}$ (Mt Mangdaeam) to $1550 \mathrm{~m}$ (Mt Halla). The majority of the natural habitats of $L$. amabile were found on mountain slopes, and some were found in rugged mountain regions. The down-facing flowers of this species not only had many blotches but also dense trichomes, and the flowering time was found to be from mid-June to mid-July. ANOVA revealed significant variations in vegetative and floral traits among the six habitats, indicating that the environment has substantial influences on the various growth parameters of $L$. amabile, such as plant height; number of leaves, bracts, papillae, and flowers; leaf angle; and lengths of the anther, longest blotch, and nectary of the petiole. In addition, the vegetative and floral traits were found closely correlated with each other under the direct impact of the environment. These findings will facilitate to find the appropriate environmental conditions for the conservation and development of L. amabile population as future lily-breeding materials.
\end{abstract}

Keywords Population diversity, Morphological traits, Floral traits, Ecogeographical habitats, Lilium amabile

\footnotetext{
${ }^{\dagger}$ The first two authors (VYN and RR) contributed equally to this work.

V. Y. Nguyen $\cdot$ R. Rai $\cdot$ J.-H. Kim $\cdot$ J.-Y. $\operatorname{Kim}^{\dagger}(\bowtie)$

Department of Horticulture, Kangwon National University,

Chuncheon 200-701, Korea

e-mail: multi-jjang@hanmail.net

R. Rai $\cdot$ J.-H. Kim

Oriental Bio-herb Research Institute, Kangwon National

University, Chuncheon 200-701, Korea

J.-K. $\mathrm{Na}^{\dagger}(\square)$

Department of Controlled Agriculture, Kangwon National

University, Chuncheon 200-701, Korea

e-mail: jongkook@kangwon.ac.kr
}

\section{Introduction}

Lilies are one of the important geophytes and these floricultural crop plants are used for the production of cut flowers, for pot plant purposes at home, park, garden, landscape decoration, medicinal purposes, as food, cosmetic, and also used for various ethnic rituals (Dhiman et al. 2018; Grassotti and Gimelli 2011). The genus Lilium comprises nearly 110 species in 7 sections, and there are more than 10,000 commercially important cultivars (Bakhshaie et al. 2016; De Jong 1974; Mathews 2007, Mc Rae 1998). With recent addition of former genus Nomocharis to Lilium, now the genus Lilium includes about 125 species (Gao and Gao 2016), and they are widely distributed throughout the world, mainly in boreal and temperate zones in the Northern Hemisphere, including the Himalayas, Southeast Asia, Japan and China, the Caucasus, and North America (Gao and Gao, 2016; McRae 1998). The east coast of Asia, especially coastal regions of the southwest and north china, is considered as the natural home of almost 59 species of wild lily and is believed to be the center of wild lily diversity (De Jong 1974).

Korea is another major center of wild lily diversity, due to diverse climatic conditions that support Lilium prosperity (Lucidos et al. 2013). Wilson (1925) first reported the distribution of different lily species in Korea. However, the distribution of wild lily species in Korea had not been studied further until Lighty (1969) reported 11 lily species in South Korea. Among 11 wild lily species, seven species were classified into Sinomartagon section, one species into Daurolirion section, and three species into Martagon section (Kim 2008; Lee 2003). Seven species belonging to the Sinomartagon section include L. amabile, L. callosum, $L$. cernuum, L. concolor, L. lancifolium, and L. leichtlini var maximowizii. However, there are only few studies conducted for morphological characteristics, habitat ecology, and environmental impacts on wild lilies, including $L$. amabile, 
Table 1 Climate characteristics of the sites of L. amabile collection

\begin{tabular}{llccc}
\hline ID & \multicolumn{1}{c}{ Habitat locality } & $\begin{array}{c}\text { Mean annual rainfall } \\
(\mathrm{mm})\end{array}$ & $\begin{array}{c}\text { Mean temperature } \\
\left({ }^{\circ} \mathrm{C}\right)\end{array}$ & $\begin{array}{c}\text { Mean relative } \\
\text { humidity }(\%)\end{array}$ \\
\hline MP & Mt. Moonphilbong, Danyang-gun, Gangwon-Do & 1900 & 9.1 & 73.0 \\
GJ & Mt. Gongjak, Hongcheon-gun, Gangwon-Do & 1405 & 10.3 & 69.5 \\
HL & Mt. Halla, JeJu-Do & 4670 & 6.55 & 80.0 \\
MB & Mt Maebong, Hongcheon, Gangwon-Do & 1000 & 10.5 & 71.0 \\
MD* & Mt Mangdaeam, Inje-gun, Gangwon-Do & 1210 & 10.1 & 69.6 \\
KB & Mt Kkotbong, Yanggu-gun, Gangwon-Do & 1000 & 10.5 & 71.0 \\
\hline
\end{tabular}

MP, Moonphilbong; GJ, Gongjak; HL, Halla; MB, Maebong; MD, Mangdaem; KB, Kkotbong.

*The climate characteristics of MD were retrieved from Wikipedia (https://en.wikipedia.org/wiki/Inje_County\#Climate)

in Korea, and rather most previous studies were carried out to identify wild lily species and habitats.

L. amabile is a flowering bulbous perennial wild lily (Kim and Lee, 1990b) and distributed from the southernmost island Jeju $\left(33^{\circ} \mathrm{N} 126^{\circ} \mathrm{E}\right)$ to the easternmost island Uleung, Korea $\left(37^{\circ} \mathrm{N} 137^{\circ} \mathrm{E}\right)$ (Synge 1980; Wilson 1925). Also, it is distributed in Liaoning province (Haw 1986) and the Manchuria, China (Chung 1965). Although flower and leaf morphology of L. amabile were reported previously (Jeong 1991; Kim and Lee 1990a; Lee 1980; Song et al. 1989), these studies provided only general information (Wilson 1925) and lacked any information about phenotypic variations among different habitats. L. amabile plants can be found both sunny and shade areas with sufficient water supply or drought-prone environment (Chung et al. 2015; Jeong 1991). On the other hand, genetic studies of L. amabile were carried out recently, revealing karyotype and B chromosome variation, cytological variations, and long terminal repeat (LTR) retro transposon diversities among diploid and B-chromosome aneuploidy has been already analyzed in the previous studies (Lee et al. 2019; Nguyen et al. 2019).

The present study was undertaken (1) to determine the difference between the vegetative and flower traits under a given environment that directly impacts the appearance of $L$. amabile and to unravel (2) correlation between them -thereby understanding the phenotypic plasticity and the habitat's geographical features of $L$. amabile-searching for the appropriate environmental type for the conservation and development of the L. amabile population.

\section{Materials and Methods}

Population survey and sample collection

The distribution sites of Lilium amabile Palibian in
Korea were surveyed to investigate geo-ecological features and its diversities, and variation for different vegetative and floral traits. Six populations representing six different eco-geographical regions/mountains in South Korea were used for the evaluation of the traits. To examine environmental conditions, climatic components of natural habitats were collected using data loggers (Table 1). The populations were consisting of 73 individuals: 24 from mountain (Mt) Moonphilbong, 14 from Mt Gongjak, 6 from Mt Halla, 7 from Mt Maebong, 17 from Mt Mangdaeam, and 6 from Mt Kkotbong (Fig. 1, Table 2). Population habitats were denoted as MP for Mt Moonphilbong, GJ for Mt Gongjak, $\mathrm{HL}$ for Mt Halla, MB for Mt Maebong, MD for Mt Mangdaeam, and KB for Kkotbong, respectively (Table 1). The vegetative traits and the floral traits of the indicated number of individuals from each population were examined on the habitats and those individuals were collected for the further study.

Location of natural habitats

The geographical data of the six natural habitats, including latitude, longitude, and altitude, were recorded using the portable GPS (Garmin Colorado 300, Garmin, Kansas, TX, USA) navigator device. Their relative locations, directions, and angles of the mountain slopes were recorded by using Google maps.

Analysis of phenotypic characteristics

Twenty-five quantitative traits, 11 vegetative and 14 floral traits, were examined for 73 individuals from the six populations for three years, 2018-2020. Eleven vegetative growth characteristics include plant height (PHT), number of leaves (NOL), leaf length at middle (LLM), leaf width at middle (LWM), leaf length at top (LLT), leaf width at top (LWT), leaf length at bottom (LLB), leaf width at 
Table 2 Geographical and environmental features of the L. amabile habitats in Korea

\begin{tabular}{|c|c|c|c|c|c|c|c|}
\hline ID & $\begin{array}{l}\text { Populati } \\
\text { on size }\end{array}$ & $\begin{array}{l}\text { Number of } \\
\text { the studied } \\
\text { lines }\end{array}$ & $\begin{array}{l}\text { Longitude } \\
\qquad\left({ }^{\circ} \mathrm{E}\right)\end{array}$ & $\begin{array}{l}\text { Latitude } \\
\left({ }^{\circ} \mathrm{N}\right)\end{array}$ & $\begin{array}{l}\text { Altitude } \\
\text { (m) }\end{array}$ & $\begin{array}{l}\text { Flowering } \\
\text { time }\end{array}$ & Habitat environment \\
\hline MP & 300 & 24 & 37.05 & 128.49 & 400 & 20-Jun & $\begin{array}{l}\text { Mountain roadside with herbs and woody plants } \\
\text { (trees with the main stem throughout the plant, } \sim 2^{-} \\
3 \mathrm{~m} \text { high). Loam soil, } 10 \% \text { humidity, sunny weather } \\
\text { with open sky. }\end{array}$ \\
\hline GJ & $<100$ & 13 & 37.45 & 128.01 & $400-750$ & 22-Jun & $\begin{array}{l}\text { Mountain roadside shaded by big trees. Dry sandy } \\
\text { soil, } 5 \% \text { humidity. }\end{array}$ \\
\hline $\mathrm{HL}$ & $<20$ & 6 & 33.2 & 126.32 & $1450-1550$ & 11-Jul & $\begin{array}{l}\text { Very small population; shaded by azaleas, bamboos, } \\
\text { and grasses. The soil of Mt.Halla is mostly com- } \\
\text { posed of volcanic ash, volcanic sand, and lapilli } \\
\text { (well-drained humus-enriched soil) and is not the } \\
\text { best for farming; } 35 \% \text { humidity. Upper part receives } \\
\text { full sun. }\end{array}$ \\
\hline MB & 100 & 7 & 37.81 & 127.81 & $400-600$ & 16-Jun & $\begin{array}{l}\text { Mountain roadside with herbs and woody plants } \\
\text { (trees with the main stem throughout the plant, } \sim 2- \\
3 \mathrm{~m} \text { high). Sandy soil, } 10 \% \text { humidity. Sunny weather } \\
\text { with open sky. }\end{array}$ \\
\hline MD & 200 & 17 & 38.05 & 128.5 & $300-400$ & 22-Jun & $\begin{array}{l}\text { Flat hills co-inhabited with herbs and shrubs (any } \\
\text { woody plant }<2.5 \mathrm{~m} \text { high). Sandy loam. Sunny } \\
\text { weather with open sky; receives full sun. }\end{array}$ \\
\hline $\mathrm{KB}$ & 100 & 6 & 38.12 & 127.51 & $339-450$ & 18-Jun & $\begin{array}{l}\text { Mountain roadside with herbs and woody plants } \\
\text { (trees with the main stem throughout the plant, } \sim 3^{-} \\
4 \mathrm{~m} \text { ). Sandy soil; sunny with open sky. }\end{array}$ \\
\hline Total & & 73 & & & & $\begin{array}{l}\text { 16-June- } \\
11-J u l y\end{array}$ & \\
\hline
\end{tabular}

MP, Moonphilbong; GJ, Gongjak; HL, Halla; MB, Maebong; MD, Mangdaeam; KB, Kkotbong Mountain.

bottom (LWB), angle the leaf (AOL) from stem, stem diameter (STD), and number of bract (NOB) per plant. Fourteen floral traits were examined for number of flower

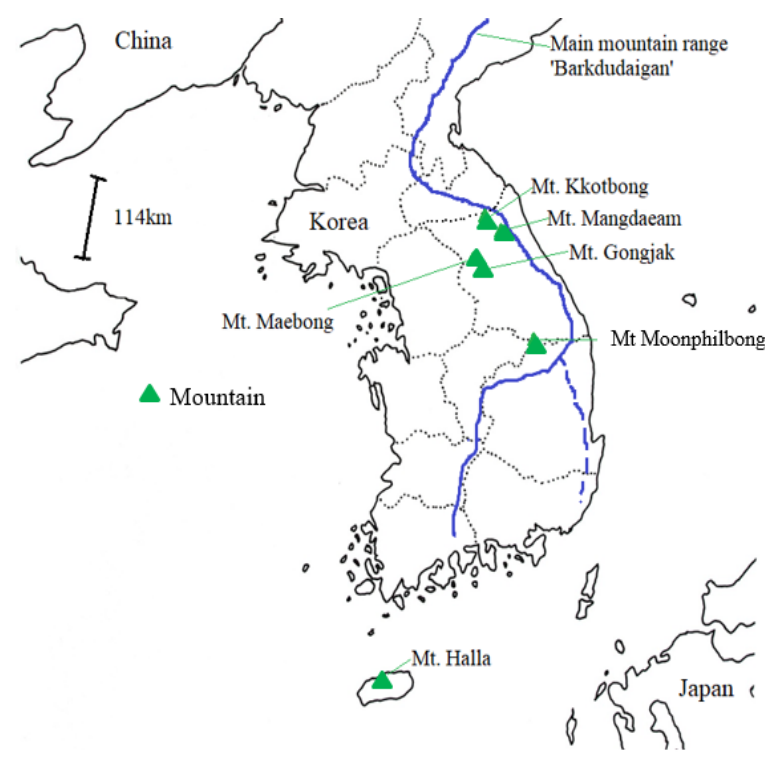

Fig. 1 Locations of the six L. amabile habitats surveyed in Korea (Blue triangles). The solid blue line represents the main mountain range "Baekdudaegan" in the Korean peninsula, and the dotted line represents the mountain range "Nakdongjeongmaek."
(NOF) per stem, length of outer tepal (LOT), width of outer tepal (WOT), length of inner tepal (LIT), width of inner tepal (WIT), blotch number in inner tepal (BNIT), length of longest blotch (LOLB), length of filament (LOF), length of anther (LOA), length of style (LOS), length of ovary (LOO), length of nectary of petiole (NOP), number of papillae (NP), and diameter of flower (DOF).

Data analysis

The data of twenty five morphological traits were subjected to various statistical analyses; descriptive analysis, analysis of variance (ANOVA), Pearson correlations among and between the traits, and principal coordinate analysis (PCoA). To test differences in each trait among six $L$. amiable populations, we applied one-way ANOVA followed by least significant difference (LSD) post hoc analyses using SPSS v.20. To analyze genotypic composition and environmental influence on the phenotype, the mean values were used to calculate genetic parameters such as the genotypic coefficient of variation (GCV), phenotypic coefficient of variation (PCV), and coefficient of variation (CV) based on Singh and Choudhary (1979). PCV and GCV were estimated based on the estimation of genotypic 
and phenotypic variance and expressed in percentage according to Burton and Devane (1953). Then, PCV and GCV were classified to $0 \sim 10 \%$ (Low), $10 \sim 20 \%$ (Moderate), and $>$ $20 \%$ (High) as suggested by Shivasubramanian and Menon (1973).

Estimations of population subdivisions (QST) were calculated according to $\mathrm{QST}=\mathrm{VAP} / \mathrm{VAP}+\mathrm{VBP}$ ) under the report for a predominantly autogamous species (Badri et al. 2015; Morgan et al. 2001; Spitze 1993), where VAP is population variance component among them and VBP within populations variance component. For each population, broad-sense heritability $\left(\mathrm{H}^{2} \mathrm{bs}\right)$ of the traits was estimated as the ratio of the genetic variance on the sum of genetic variance and environmental variance estimated according to Badri (2007) and categorized as $0 \sim 10 \%$ (Low), $10 \sim 20$ (Moderate), and $>20 \%$ (High). The genetic advance as percent mean (GAM) was calculated as suggested by Johnson et al. (1955) and categorized as $0 \sim 10 \%$ (Low), $10 \sim 20 \%$ (Moderate), and $>20 \%$ (High). The Pearson correlations between measured traits were estimated using SPSS software (SPSS Inc. Chicago, IL, USA) and used PCoA imbedded in GENALEX $6.51 \mathrm{~b} 2$ software (http://biology. anu.edu.au/GenAlEx/). The clustering analysis of individual plants was performed based on dissimilarity matrix using Euclidean distances estimated on the mean lines' values with the ward's method in XLSTAT version 2015.1 (Addinsoft Inc., New York, USA).

\section{Results}

Distribution, compositional features of the populations, and the natural growth environment of $L$. amabile in South Korea

To investigate distribution, features of population, and habitat environment of L. amabile in Korea, L. amabile populations were surveyed in six mountains, Mt Moonphilbong, Mt Gongjak, Mt Maebong, Mt Halla, and Mt Kkotbong (Fig. 1). Among the surveyed mountains, Mt Mangdaeam is the lowest habitat with altitude of $300 \mathrm{~m}$ and Mt Halla the highest with altitude of $1550 \mathrm{~m}$. A large distribution of $L$. amabile was observed at an altitude of $300 \sim 600 \mathrm{~m}$, in which population size was more than 100 individuals. In case of Mt Halla habitat at an altitude of $1450 \mathrm{~m} \sim 1550$ $\mathrm{m}$, population size was diminished to less than 20 individuals, and habitats are mixed with azalea, bamboo, and grasses (Table 2). The soil of Mt Halla, mostly made out of volcanic ash, volcanic sand, and lapilli (good drain humus soil), is not suitable for farming due to low humidity of $35 \%$. From 400 to $750 \mathrm{~m}$ altitude of Mt Gongjak, less than 100 individuals were scattered over the mountain completely covered by big trees and grasses on the dried sandy soil with $5 \%$ humidity. However, in an altitude of 300 to $450 \mathrm{~m}$ (Mt Moonphilbong, Mt Maebong, Mt Mangdaeam, and Mt Kkotbong), populations were large around $100 \sim 300$ individuals. But the habitat of L. amablie population in the mountainous areas was very different. At rocky Mt Moonphilbong, habitats were full of herbaceous plant and woody plant (a tree with a straight main stem, about $2 \sim 3 \mathrm{~m}$ high) on loam soil with of $10 \%$ humidity. Habitat in Mt Maebong was very sunny and consisting of herbs and woody plants in sandy soil with $10 \%$ humidity. Mt Mangdaeam habitat is on flat sunny hills, and $L$. amabile grows with herbs and shrubs (woody plants less than $2.5 \mathrm{~m}$ high) on sandy loam soil (Table 2).

In this study, the peak of blooming of the L. Amabile in South Korea was between 16 June and 11 July (Table 2). The earliest blooming was observed at Mt Maebong and the latest at Mt Halla. Flowering time tended to be delayed with elevation of latitude. At the peak of blooming, the average temperature and humidity was between $18 \sim 23^{\circ} \mathrm{C}$ and $80 \sim 82 \%$.

Diversities and variation in vegetative traits among the studied populations

Surveyed region was not large except for Mt Halla (Fig. 1), but significant variations in growth traits were detected from different geo-graphical regions (Table 3). The plant height (PHT) were ranged from 31.51 to $89.08 \mathrm{~cm}$, the tallest one recorded from Kkotbong populations and the shortest one from Maebong populations. The highest number of leaves were found from Kkotbong populations (i.e 70), whereas the least number of leaves from Mangdaeam populations. Likewise, Kkotbong populations showed the thickest stem diameter with the average of $5.22 \mathrm{~mm}$ while the thinnest stem diameter was recorded from Mangdaeam populations with the average of $3.19 \mathrm{~mm}$. Halla and Maebong populations showed high leaf density with 1.28 and 1.76 leaf per centimeter compared to the rest with $0.8 \sim 0.9$. The leaf shape of $L$. amabile was a long and narrow, and leaves at the middle of plants were the largest in size, followed by those at bottom and top except for Halla population, in which leaves at the bottom was the largest leaf. Intriguingly, middle leaf size of Mt Gongjak population exhibited significantly bigger than those in upper and lower leaves (Table 3). The leaf angle (AOL) ranged from 38.46 to $85.83^{\circ}$, and the largest leaf angle was observed in Mt Halla and Mt Gongjak population, 
Table 3 ANOVA for 11 vegetative traits among the six L. amabile populations

\begin{tabular}{|c|c|c|c|c|c|c|c|c|c|c|c|}
\hline ID & PHT & NOL & LLM & LWM & LLT & LWT & LLB & LWB & $\mathrm{AOL}$ & STD & NOB \\
\hline MP & $49.33 \pm 8.37^{\mathrm{bc}}$ & $40.25 \pm 10.49^{\mathrm{b}}$ & $5.14 \pm 1.15^{\mathrm{cd}}$ & $0.83 \pm 0.16^{\mathrm{a}}$ & $2.64 \pm 1.10^{\mathrm{b}}$ & $0.68 \pm 0.18^{\mathrm{bc}}$ & $4.22 \pm 1.31^{\mathrm{b}}$ & $0.74 \pm 0.17^{\mathrm{bc}}$ & $38.46 \pm 7.36^{c}$ & $3.46 \pm 0.44^{\mathrm{b}}$ & $2.46 \pm 1.53^{\mathrm{bc}}$ \\
\hline GJ & $52.10 \pm 8.12^{b}$ & $40.62 \pm 10.52^{b}$ & $8.31 \pm 1.46^{\mathrm{a}}$ & $0.96 \pm 0.14^{\mathrm{a}}$ & $4.85 \pm 1.66^{\mathrm{a}}$ & $0.80 \pm 0.21^{\mathrm{b}}$ & $5.58 \pm 1.74^{\mathrm{ab}}$ & $0.80 \pm 0.18^{\mathrm{ab}}$ & $81.23 \pm 9.24^{\mathrm{a}}$ & $3.47 \pm 0.75^{\mathrm{b}}$ & $1.08 \pm 0.28^{\mathrm{c}}$ \\
\hline $\mathrm{HL}$ & $41.00 \pm 6.60^{\mathrm{cd}}$ & $52.50 \pm 11.59^{\mathrm{a}}$ & $3.87 \pm 0.68^{\mathrm{cd}}$ & $0.80 \pm 0.11^{\mathrm{a}}$ & $3.77 \pm 0.52^{\mathrm{ab}}$ & $1.11 \pm 0.08^{\mathrm{a}}$ & $5.13 \pm 0.53^{\mathrm{ab}}$ & $0.95 \pm 0.08^{\mathrm{ab}}$ & $85.83 \pm 1.86^{\mathrm{a}}$ & $3.55 \pm 0.97^{\mathrm{b}}$ & $1.33 \pm 0.52^{\mathrm{c}}$ \\
\hline MB & $31.51 \pm 4.67^{\mathrm{d}}$ & $55.57 \pm 17.9^{\text {ab }}$ & $4.74 \pm 0.62^{d}$ & $0.53 \pm 0.11^{\mathrm{b}}$ & $2.44 \pm 0.0 .75^{b}$ & $0.54 \pm 0.13^{\mathrm{c}}$ & $4.00 \pm 1.35^{\mathrm{b}}$ & $0.56 \pm 0.10^{\mathrm{c}}$ & $49.71 \pm 7.67^{b}$ & $3.64 \pm 0.75^{b}$ & $3.57 \pm 1.13^{\mathrm{b}}$ \\
\hline MD & $42.16 \pm 7.37^{\mathrm{bcd}}$ & $37.59 \pm 13.51^{\mathrm{b}}$ & $6.12 \pm 1.02^{\mathrm{bc}}$ & $0.76 \pm 0.17^{\mathrm{a}}$ & $2.65 \pm 0.75^{\mathrm{b}}$ & $0.69 \pm 0.14^{\mathrm{bc}}$ & $5.01 \pm 1.04^{\mathrm{ab}}$ & $0.77 \pm 0.20^{\text {abc }}$ & $49.06 \pm 7.95^{\mathrm{b}}$ & $3.19 \pm 0.48^{\mathrm{b}}$ & $4.18 \pm 1.29^{b}$ \\
\hline $\mathrm{KB}$ & $89.08 \pm 10.83^{\mathrm{a}}$ & $70.00 \pm 21.71^{\mathrm{a}}$ & $7.10 \pm 1.18^{\mathrm{ab}}$ & $0.97 \pm 0.19^{\mathrm{a}}$ & $3.47 \pm 1.06^{\mathrm{ab}}$ & $0.74 \pm 0.21^{\mathrm{b}}$ & $6.22 \pm 0.72^{\mathrm{a}}$ & $0.99 \pm 0.16^{\mathrm{a}}$ & $57.17 \pm 6.49^{\mathrm{b}}$ & $5.22 \pm 0.85^{\mathrm{a}}$ & $6.50 \pm 1.87^{\mathrm{a}}$ \\
\hline CV (\%) & 104.82 & 79.32 & 86.87 & 55.99 & 103.95 & 70.11 & 53.34 & 51.59 & 155.58 & 54.83 & 197.63 \\
\hline LSD5\% & 13.12 & 13.36 & 1.47 & 0.16 & 1.16 & 0.18 & 1.19 & 0.17 & 17.96 & 0.67 & 1.67 \\
\hline PCV & 33.84 & 36.54 & 30.67 & 23.64 & 44.45 & 29.78 & 29.34 & 25.61 & 47.05 & 23.06 & 69.99 \\
\hline GCV & 29.69 & 21.07 & 24.32 & 15.19 & 28.12 & 19.00 & 13.33 & 13.40 & 44.38 & 14.89 & 55.31 \\
\hline $\mathrm{H}_{\text {bs }}^{2}(\%)$ & 76.98 & 33.24 & 62.88 & 41.26 & 40.02 & 40.68 & 20.65 & 27.38 & 85.79 & 41.67 & 62.46 \\
\hline $\mathrm{Q}_{\text {ST }}$ & 0.98 & 0.88 & 0.96 & 0.91 & 0.90 & 0.90 & 0.81 & 0.85 & 0.99 & 0.91 & 0.96 \\
\hline GAM & 53.66 & 25.02 & 39.73 & 20.10 & 36.65 & 24.96 & 12.48 & 14.45 & 67.70 & 19.79 & 90.04 \\
\hline
\end{tabular}

PHT, plant height; NOL, number of leaves; LLM, leaf length at the middle; LWM, leaf width at the middle; LLT, leaf length at the top; LWT, leaf width at the top; LLB, leaf length at the bottom; LWB, leaf width at the bottom; AOL, angle of leaf; STD, stem diameter; and NOB, number of bracts

The values shown are means \pm SD. Uppercase letters in trait data denote significant the differences based on the least significant difference post-hoc analysis (LSD; $P<0.05$ ) after one-way ANOVA.

and the smallest in Mt Moonphillbong.

The phenotypic coefficient of variation (PCV) was greater than a genetic coefficient of variation $(\mathrm{GCV})$ in all studied traits, indicating that habitat environment had an impact on all surveyed characteristics. However, the difference between PCV and GCV showed different levels of the influence of environmental factors on the traits. The biggest difference between PCV and GCV is observed in the LLT (44.45 vs 28.12), LLB (29.34 vs 13.33), NOL (36.54 vs 21.07), and NOB (69.99 vs 55.31), indicating that these traits are highly affected by geographical environment and that they can be improved under an appropriate environmental conditions. Heritability $\left(\mathrm{H}^{2}{ }_{\text {bs }} \%\right)$ of 11 growth traits were high as $20.65 \sim 85.79 \%$, which can be improved by the selective method. Characteristics of PHT, LLM, LWM, LLT, LWT, AOL, STD, and NOB exhibited high heritability and genetic advance. Thus, these eight traits can be improved by growing conditions. On the other hand, NOL, LLB, and LWB may be regulated by an additive gene action.

Diversities and variations for floral traits among the studied populations

To investigate variation in floral traits, fourteen floral characteristics were examined for all individuals from six populations. The average number of flowers ranged $1 \sim 3$, 3 in Mt Kkotbong population and 1 in Mt Gongjak population. The average length of outer tepal (LOT) was recorded as the longest with $5.11 \mathrm{~mm}$ in Mt Gongjak population and the shortest with $4.01 \mathrm{~mm}$ in Mt Kkotbong population. Average length of inner tepal (LIT) was recorded as the longest with $5.03 \mathrm{~mm}$ in Mt Gongjak population and the shortest with $4.05 \mathrm{~mm}$ in Mt Kkotbong. The blotch number in inner tepal (BNIT) ranged from 48.7 to 82.7, and most abundant on flowers in Mt Maebong and Mt Moonphilbong population. The length of the longest blotch (LOLB) ranged from 2.28 (Mt Halla) to $6.86 \mathrm{~mm}$ (Mt Maebong). The length of filament (LOF) ranged from 2.99 to $3.61 \mathrm{~cm}$, and the variation of the length of anther (LOA) ranged from 1.19 to $3.10 \mathrm{~cm}$. The length of style (LOS) varied from 2.41 to $2.97 \mathrm{~cm}$. Mt Halla population exhibited the longest length of ovary (LOO) as $1.63 \mathrm{~cm}$, whereas Mt Mangdaeam population showed the shortest LOO as 1.02. The length of nectary of petiole (NOP) ranged from 1.63 to $3.13 \mathrm{~cm}$, with the longest recorded from Mt Halla population and the shortest from measured for Mt Mangdaeam. In case of the number of papillae (NP), the measured variation ranged from 3.00 to 19.43 . The highest NP was recorded from Mt Maebong population and the lowest from Mt Halla. The flower diameter (DOF) varied from 4.82 to $6.08 \mathrm{~cm}$.

As per estimation demonstrated, all floral characteristics showed significant variations among the habitats. These results showed that the flower characteristics in each region have their own specific characteristics. L. amabile in Mt Moonphilbong and Mt Maebong produced thick flowers with numerous black dots on the petals. Also, 
Table 4 ANOVA for 14 floral traits among the six L. amabile populations

\begin{tabular}{|c|c|c|c|c|c|c|c|c|c|c|c|c|c|c|}
\hline ID & NOF & LOT & WOT & LIT & WIT & BNIT & LOLB & LOF & LOA & LOS & LOO & NOP & NP & DOF \\
\hline MP & $1.42 \pm 0.58^{b}$ & $4.84 \pm 0.75^{\text {ab }}$ & $1.49 \pm 0.19^{\mathrm{a}}$ & $4.63 \pm 0.66^{20}$ & $1.89 \pm 0.30^{\mathrm{a}}$ & $76.50 \pm 22.27^{\mathrm{a}}$ & $3.90 \pm 2.24^{\mathrm{wox}}$ & $3.38 \pm 0.43^{\text {ab }}$ & $1.29 \pm 0.28^{6}$ & $2.74 \pm 0.59^{\text {ab }}$ & $1.40 \pm 0.51^{\text {ab }}$ & $1.87 \pm 0.37^{6}$ & $13.46 \pm 4.39^{6}$ & $6.07 \pm 1.09^{\mathrm{a}}$ \\
\hline GJ & $1.15 \pm 0.38^{b}$ & $5.11 \pm 0.46^{\mathrm{a}}$ & $1.34 \pm 0.20^{\mathrm{ab}}$ & $5.03 \pm 0.47^{\mathrm{a}}$ & $1.67 \pm 0.28^{\mathrm{a}}$ & $62.69 \pm 20.24^{\text {ab }}$ & $2.59 \pm 1.24^{\mathrm{bc}}$ & $3.50 \pm 0.42^{\mathrm{ab}}$ & $1.19 \pm 0.23^{b}$ & $2.97 \pm 0.34^{\text {ab }}$ & $1.45 \pm 0.30^{\text {ab }}$ & $2.16 \pm 0.89^{b}$ & $5.49 \pm 2.02^{\mathrm{cd}}$ & $5.72 \pm 0.91^{\text {ab }}$ \\
\hline HL & $1.83 \pm 0.75^{b}$ & $4.62 \pm 0.25^{\mathrm{ab}}$ & $1.45 \pm 0.08^{\mathrm{a}}$ & $4.53 \pm 0.29^{\text {ab }}$ & $1.80 \pm 0.17^{\mathrm{a}}$ & $58.00 \pm 12.00^{\mathrm{ab}}$ & $2.28 \pm 0.55^{\mathrm{c}}$ & $3.03 \pm 0.25^{\mathrm{b}}$ & $3.10 \pm 0.18^{\mathrm{a}}$ & $3.72 \pm 0.39^{\mathrm{a}}$ & $1.63 \pm 0.08^{\mathrm{a}}$ & $3.13 \pm 0.43^{\mathrm{a}}$ & $3.00 \pm 1.79^{\mathrm{d}}$ & $4.82 \pm 0.29^{\mathrm{b}}$ \\
\hline MB & $2.00 \pm 0.82^{b}$ & $4.61 \pm 0.62^{a b}$ & $1.36 \pm 0.16^{\mathrm{ab}}$ & $4.44 \pm 0.56^{\mathrm{ab}}$ & $1.81 \pm 0.19^{\mathrm{a}}$ & $82.86 \pm 17.40^{\mathrm{a}}$ & $6.86 \pm 1.35^{\mathrm{a}}$ & $3.61 \pm 0.41^{\mathrm{a}}$ & $1.38 \pm 0.23^{\mathrm{b}}$ & $2.67 \pm 0.29^{b}$ & $1.26 \pm 0.21^{\mathrm{ab}}$ & $1.87 \pm 0.28^{\mathrm{b}}$ & $19.43 \pm 5.56^{\mathrm{a}}$ & $5.87 \pm 0.63^{\text {ab }}$ \\
\hline $\mathrm{MD}$ & $1.41 \pm 0.71^{\mathrm{b}}$ & $4.13 \pm 0.61^{\mathrm{b}}$ & $1.19 \pm 0.14^{\mathrm{b}}$ & $4.14 \pm 0.51^{\mathrm{b}}$ & $1.60 \pm 0.20^{\mathrm{a}}$ & $48.71 \pm 16.67^{b}$ & $3.82 \pm 1.56^{\mathrm{bc}}$ & $2.99 \pm 039^{b}$ & $1.21 \pm 0.27^{\mathrm{b}}$ & $2.41 \pm 0.60^{\mathrm{b}}$ & $1.02 \pm 0.10^{\mathrm{b}}$ & $1.63 \pm 0.34^{\mathrm{b}}$ & $7.18 \pm 3.64^{\text {cd }}$ & $4.97 \pm 0.82^{\mathrm{ab}}$ \\
\hline KB & $3.00 \pm 0.63^{\mathrm{a}}$ & $4.01 \pm 0.63^{\mathrm{b}}$ & $1.35 \pm 0.18^{\text {ab }}$ & $4.05 \pm 0.77^{b}$ & $1.79 \pm 0.26^{\mathrm{a}}$ & $68.00 \pm 7.62^{\mathrm{ab}}$ & $5.08 \pm 1.36^{\text {ab }}$ & $3.05 \pm 0.55^{\mathrm{ab}}$ & $1.28 \pm 0.10^{b}$ & $2.43 \pm 0.45^{\mathrm{b}}$ & $1.22 \pm 0.08^{\mathrm{ab}}$ & $1.69 \pm 0.36^{b}$ & $18.33 \pm 4.32^{\text {ab }}$ & $6.08 \pm 0.72^{\mathrm{a}}$ \\
\hline CV (\%) & 116.70 & 31.68 & 30.95 & 27.28 & 24.59 & 68.71 & 119.09 & 26.69 & 137.91 & 48.38 & 55.32 & 76.58 & 186.38 & 33.33 \\
\hline LSD5\% & 0.66 & 0.60 & 0.17 & 0.54 & 0.23 & 18.37 & 1.83 & 0.39 & 0.48 & 0.66 & 0.32 & 0.53 & 5.45 & 0.84 \\
\hline $\mathrm{PCV}$ & 50.55 & 15.78 & 15.03 & 14.45 & 15.57 & 33.63 & 56.70 & 14.39 & 43.01 & 28.52 & 29.13 & 32.76 & 63.67 & 17.93 \\
\hline GCV & 31.48 & 8.22 & 8.09 & 6.92 & 5.69 & 17.93 & 31.34 & 6.72 & 39.21 & 11.70 & 14.07 & 20.72 & 52.42 & 8.41 \\
\hline $\mathrm{H}_{b s}^{2}(\%)$ & 38.78 & 27.16 & 28.99 & 22.94 & 13.36 & 28.43 & 30.55 & 21.82 & 83.13 & 16.82 & 23.35 & 39.99 & 67.77 & 21.99 \\
\hline $\mathrm{Q}_{S T}$ & 0.90 & 0.85 & 0.85 & 0.82 & 0.74 & 0.85 & 0.86 & 0.81 & 0.98 & 0.78 & 0.82 & 0.90 & 0.96 & 0.82 \\
\hline GAM & 40.83 & 8.83 & 8.98 & 6.83 & 4.29 & 19.69 & 35.69 & 6.47 & 73.65 & 9.88 & 14.01 & 26.99 & 88.89 & 8.12 \\
\hline
\end{tabular}

NOF-Number of flowers, LOT-Length of outer tepal, WOT-Width of outer tepal, LIT-Length of inner tepal, WIT-Width of inner tepal, BNIT-Blotch number in inner tepal, LOLB-Length of longest blotch, LOF-Length of filament, LOA-Length of anther, LOS-Length of style, LOO-Length of ovary, NOP-Length of nectary of petiole, NP-Number of papillae, DOF-Diameter of flower.

Values shown are means \pm SD. Uppercase letters in trait data denote significant differences based on least significant difference post hoc analysis (LSD; $P<0.05$ ) after one-way ANOVA

flowers of Mt Maebong population showed numerous papillae on the inner tepal. Mt Mangdaeam population showed the smallest indices of $L$. amabile in most floral traits. In contrast, most indices were bigger in Mt Kkotbong population. L. amabile in Mt Gongjak exhibited single cotton and little papillae on the tepal. One of the most intriguing findings among the surveyed populations was that $L$. amabile population at Mt Halla exhibited exceptionally long anther and the nectary of petiole (Table 4).

The phenotypic coefficient of variation (PCV) is greater than a genotypic coefficient of variation (GCV) in all studied floral traits. This showed the impact of environmental factors on the surveyed characteristics. However, the distance between PCV and GCV showed different levels of the influence of environmental factors on the traits. The biggest differences between PCV and GCV were observed in NOF (50.55; 31.48), BNIT (33.63; 17.93), LOLB (56.70; 31.34), LOS (28.52; 14.07), and LOO (29.13; 14.07), respectively. The heritability $\left(\mathrm{H}_{b s}^{2} \%\right)$ estimation of all 14 floral traits ranged from 13.36 to $83.13 \%$. These traits possessed high heritability except for WIT and LOS, which can be improved by the selective method. NOF, LOLB, LOA, NOP, and NP traits have possessed high heritability and high genetic advances. However, LOT, WOT, LIT, and DOF traits have demonstrated high heritability but low genetic advances. Thus, in the studied traits, NOF, LOLB, LOA, NOP, NP can be improved by growing condition. LOT, WOT, LIT, and DOF traits may be regulated by an additive gene action.
Correlation among the vegetative and floral traits

Analysis of the Pearson correlations was conducted for 300 possible correlations among the measured traits, resulting in 122 pairs of significant correlations among the traits. Among them, 90 pairs showed very significant correlations, in which 75 exhibited positive correlation while 15 pairs showed negative correlations (Table 5). Most correlations between the parameters of vegetative (aerial) growth were positive, and also not most but many pairs exhibited positive correlations among floral traits (Table 5). The flower numbers (NOF) were positively correlated with PHT, NOL, STD, NOB and NP. The LOT, WOT, LIT, and WIT were positively correlated with most of floral traits. The NP was negatively correlated with LLT, LWT, LLB, and AOL, but it was positively correlated with NOB, NOF, BNIT, LOLB, and DOF (Table 5).

Principal coordinates analysis $(\mathrm{PCOA})$ resulted in three principal coordinates, relevant to the morphological variations. These three principal coordinates accounted for $52.16 \%$ of the total variations. The first and second coordinates accounted for $21.21 \%$ and $19.66 \%$ of the total variations, respectively (Fig. 2). PCoA analysis revealed a significant separation between vegetative and floral traits except for NOF, number of flower, which exhibited close relationship with vegetative traits rather than floral traits (Fig. 2). There were positive correlations among NOF, PHT, NOL, STD, and NOB and among AOL, LLT, LWT, LWB, LLB, and LWM (Fig. 2). Similarly most floral 
Table 5 Phenotypic correlation coefficient among 25 quantitative traits in L. amabile palibian

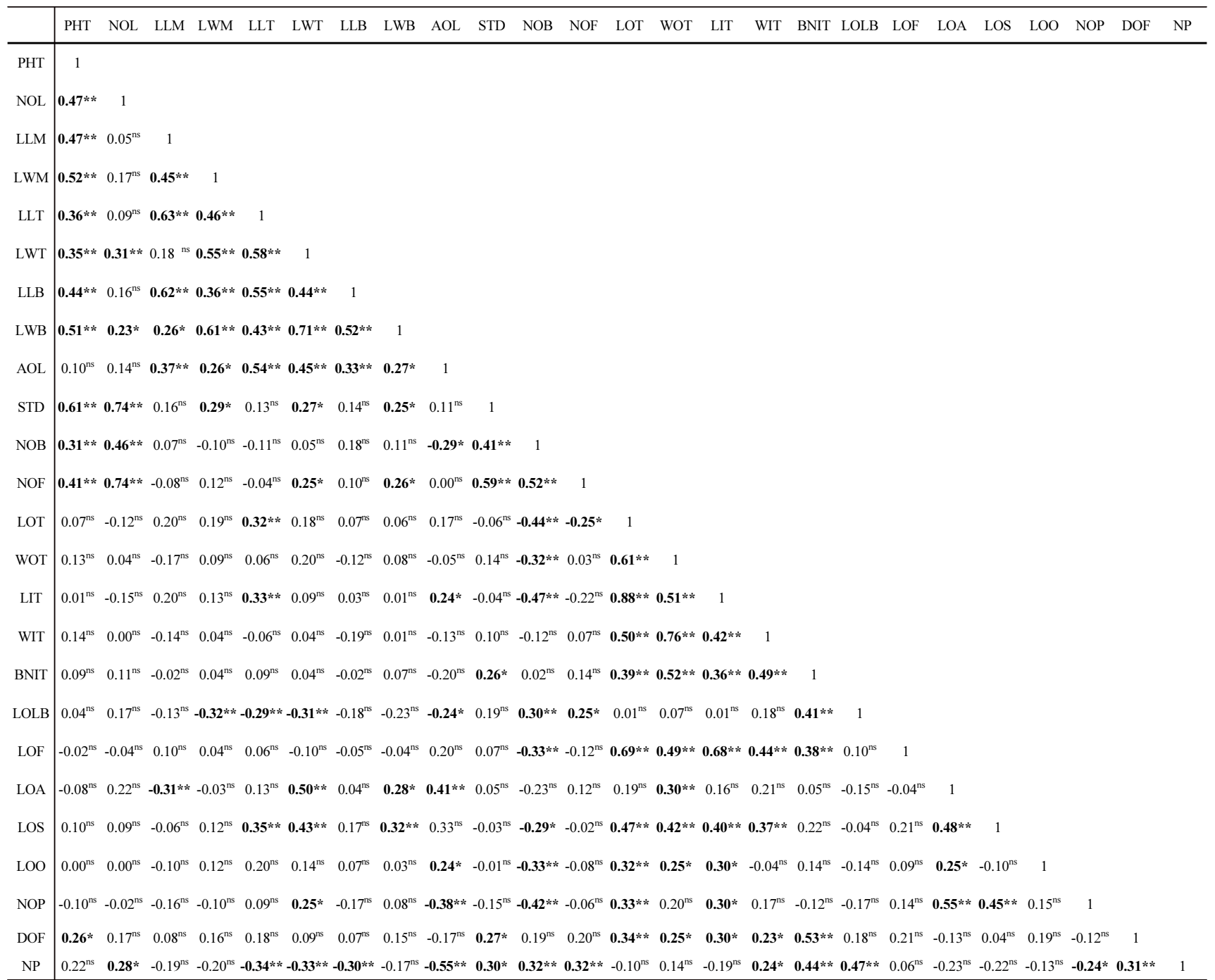

PHT, plant height; NOL, number of leaves; LLM , leaf length at the middle; LWM, leaf width at the middle; LLT, leaf length at the top; LWT, leaf width at the top; LLB, leaf length at the bottom; LWB, leaf width at the bottom; AOL, angle of leaf; STD, stem diameter; NOB, number of bracts; NOF, number of flowers; LOT, length of the outer tepal; WOT, width of the outer tepal; LIT, length of the inner tepal; WIT, width of the inner tepal; BNIT, blotch number in the inner tepal; LOLB, length of the longest blotch; LOF, length of filament; LOA, length of anther; LOS, length of style; LOO, length of ovary; NOP, length of the nectary of petiole; NP, number of papillae; DOF, diameter of flower.

$* P=0.05$, significant; ${ }^{* *} P=0.01$, highly significant; ns: not significant.

traits except for NOF exhibited close relationships. Among floral traits, there were close relationships among LIT, LOT, LOS, LOA, LOO, NOP, LOF, WOT, and WIT, and among BNIT, DOF, LOLB, and NP (Fig. 2).

Genetic diversity among the individuals within the sampled populations

Based on the characteristics of 25 morphological traits, a tree-shaped diagram was generated to show genetic relationships among L. amabile individuals from the six habitats (Fig. 1). The hierarchical cluster analysis was performed to examine the aggregation patterns of 73 lines

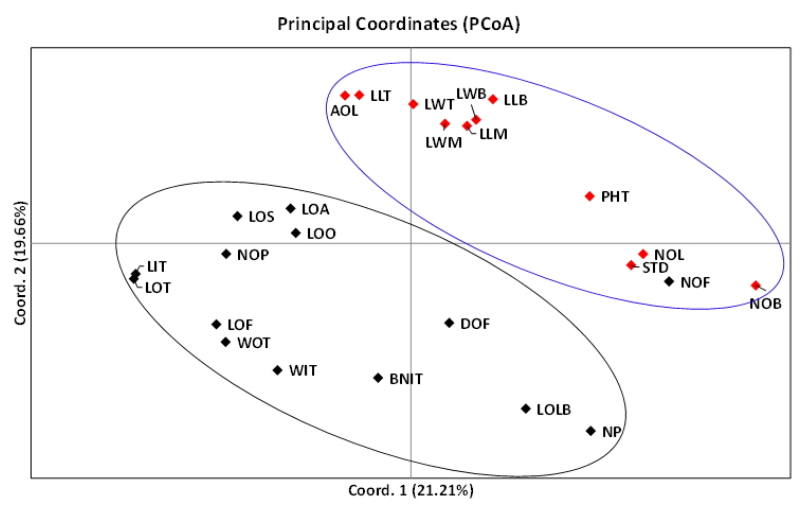

Fig. 2 PCoA analysis based on 25 morphological traits. Red and black rhombi depict vegetative and floral traits, respectively 


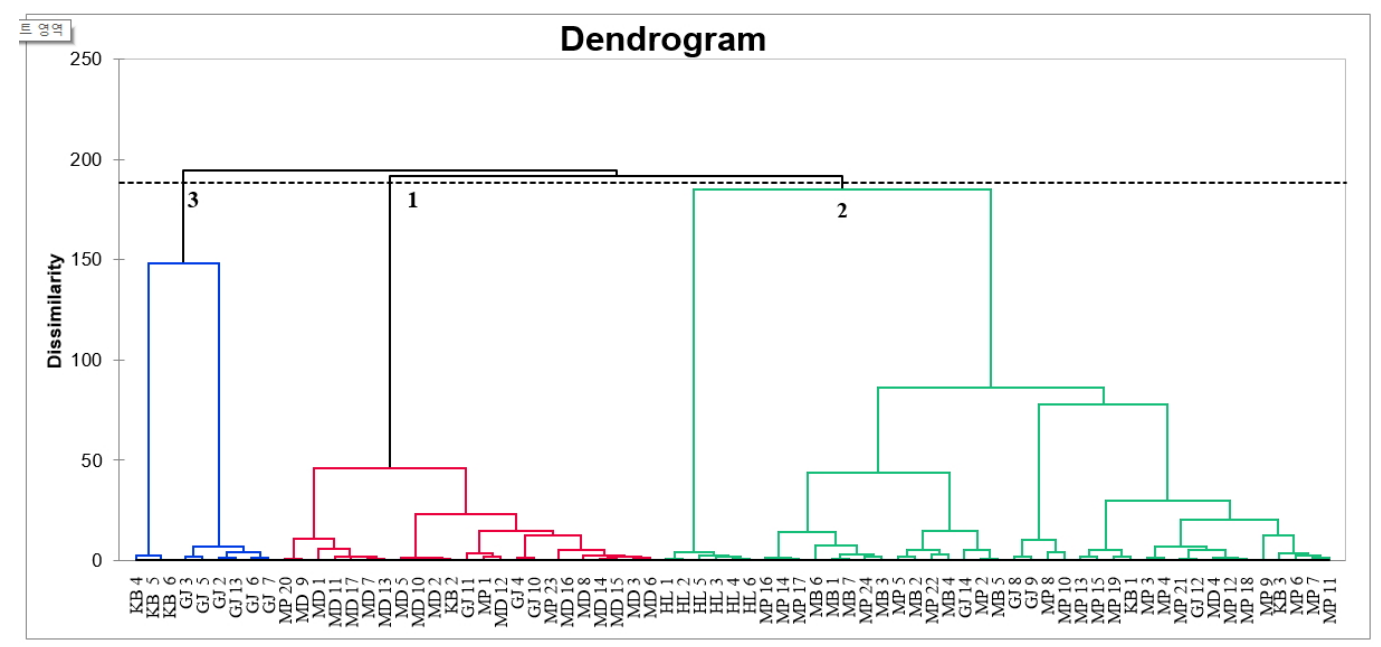

Fig. 3 Dendrogram based on the morphological relationships among the L. amabile individuals from six different habitats in Korea

of L. amabile, resulting in three groups (Fig. 3). The subclasses were classified based on morphology. The group 1 was consisting of 23 lines including each 3 from Moonphilbong and Gongjak, 16 from Mangdaeam, and 1 line from Kkotbong. This groups included those individuals with the smallest average of the traits. The group 2 was comprised of 41 lines, 21 from Moonphilbong, 4 from Gongjak, 6 from Halla, 7 from Maebong, 1 from Mangdaeam and 2 from Kkotbong. The second group is the group with the average of small vegetative traits but the largest floral traits.The group 3 consisted of 9 lines including 6 lines from Gongjak and 3 from Kkotbong. This group was characterized with a group with higher average in vegetative and floral traits. Taken together, the cluster analysis revealed that the individuals in the same group are closely related to each other in morphological characteristics.

\section{Discussion}

Lilium, as one of the major genus of geophytes, is grown worldwide for diverse ornamental purposes. This genus possesses a great diversity in many horticultural traits which is manifested in flower color, shape, size, fragrance, disease resistance, and many physiological characteristics (Dhiman et al. 2015). Lilium has comprised seven sections, among which three sections, Archelirion, Leucolirion, and Sinomartagon, are considered as the major economic groups likely due to the availability of the wide genetic diversities and various morphological characteristics. Wild lily species differ in crossability more or less, but the wild species $(2 n=2 x=24)$ produces fertile hybrids within each sections (McRae 1998; Van Tuyl et al. 2011). L. amabile, one of the endemic wild lily species in Korea, belongs to the section of Sinomartagon, and it could provide not only a key for understanding evolutionary pass of Korean wild lilies but also an important material for the new novel breeding of the Lilium. However, many endemic species are getting threatened by global climate change as well as habitat destruction by human. Therefore, the understanding of endemic species, including the levels and forms of genetic variations, would be crucial for the successful protection, and utilization of rare and endangered species (Dhiman et al. 2018).

In this study, it was examined whether eco-geographical difference in the Korean Peninsula could result in correlated variations in morphological characteristics of $L$. amabile. The difference in the habitat environment caused significant morphological changes of $L$. amabile in both vegetative and floral traits, and some degree of distinctive regional characteristics was observed in some populations. L. amabile in the Mt Moonphilbong grows on steep hills with grasses and small trees, and it has small leaf angle $\left(38.46^{\circ}\right)$ and small leaf size that likely help to reduce direct exposure to sunlight and water loss in arid climates (Fig. 4A). L. amabile plants from Mt Halla habitat with grasses, azaleas (shrub) and bamboos showed a tendency to grow tilting towards sunlight. Their leaf blade spreads nearly perpendicular to the stem and the top leaf size is long and wide to receive maximum sunlight (Fig. 4B). In Mt Gongjak, L. amabile grows under the shade of big trees, resulting in a large leaf angle with tall stems and long and thin leaves likely to receive the maximum amount of sunlight (Fig. 4C). In the Kkotbong region, $L$. amabile populations showed a large variation in vegetative growth traits compared to other populations. Among floral 


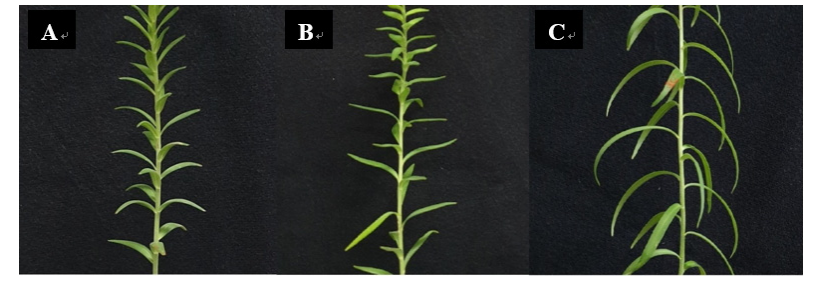

Fig. 4 Leaf morphological variations of L. amabile among different geographical regions of Korea. A. Normal type (Mt Moonphilbong, Mt Mangdaeam, Mt Maebong, and Mt Kkotbong), B. Short-straight-leaf perpendicular to the stem (Mt Halla), C. Long curved leaf with a wide leaf angle (Mt Gongjak).

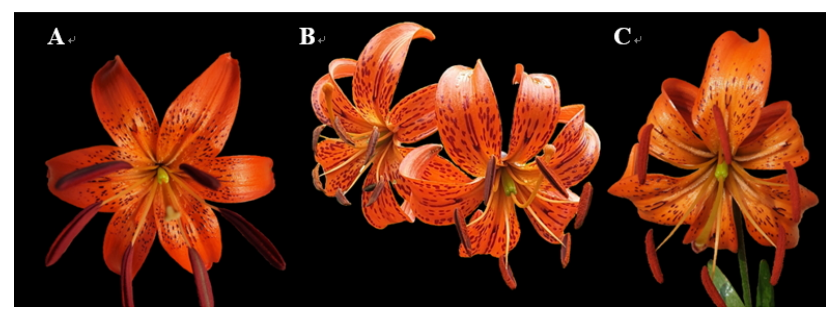

Fig. 5 Variations in L. amabile flower color and blotch among different habitats in Korea. The flowers showed distinctive regional characteristics. Flowers with A) orange-red color and small blotches from Mt Halla and Mt Mangdaeam; B) orange-red color and large blotches from Mt Moonphilbong, Mt Maebong, and Mt Kkotbong; and C) orange color with small blotches from Mt Gongjak.

traits of Mt Halla population, the length of anther, style, ovary, nectary of petiole is longer than those in other populations (Fig. 5A, Table 4). Population from Mt Gongjak exhibited a large leaf angle, long and thin leaves, and few bracts (Fig. 4C, table 3). Plants in Mt Moonphilbong was medium in height among six populations, but flower has large diameter, many blotches on the tepal, and vivid color (Fig. 5B, Table 3, 4). In Mt Maebong, L. amabile showed characteristics of arid area plants by small thick leaves and many big blotches in tepal (Fig. 4A Fig. 5B, Table 3 4).

Taken together, our results showed that habitat has strong effects on the morphological characteristics of $L$. amabile (Table 3 4), indicating the geographical characteristics of habitat contribute differently to ecological diversification most likely due to different environment. This may explains why PCV was higher than GCV in all surveyed traits (Table $3 \sim 4$ ), which implies that $L$. amabile may be sensitive to environment changes and adapted to such environment. Similar to morphological changes observed in L. amabile, another Korean wild lily, L. tsingtauense, showed morphological changes in response to habitat environment. It developed verticillate leaves at the upper parts of plants, which could be another form of ecological adaptation to receive maximum sunlight because its habitats were under the shade of trees and shrubs (Lim 2013) as seen at some of $L$. amabile habitats. The geographical variation in morphology reveals phenotypic modifications to habitat environment and evolutionary pattern of plant species, and such morphological changes specify the local regional deviations (Du et al. 2014; Ellison et al. 2004). Also, the patterns of species distribution in different zones could be a consequence by various interacting factors, such as geographical features, competition and dynamic of regional species, regional soil conditions, and environmental variables (Criddle et al. 2003; Eriksson. 1996). Most of the lilies thriving in South Korea are colored, and those presenting varied flower colors and shapes receive the greatest ornamental and commercial value. The flowers of L. amabile have a turk's-cap shape. The distinctive characteristic of $L$. amabile is the presence of white, stiff hairs covering the entire plant.

\section{Conclusion}

This study showed that morphological traits are useful tools for finding variation within and among populations of L. amabile. Our results suggest that the evolutionary trend of vegetative and floral traits could be related to the selective pressure to better adaptation to the given environmental conditions, especially extreme environment conditions. Intriguingly, it was observed that significant morphological variations in $L$. amabile occurred in relatively small region, suggesting that $L$. amabile may be a fast adapting species to local climates as seen many invasive plant species. Further population and genetic studies would give more insights of $L$. amabile morphological variations in a broad area with significant environmental changes.

\section{Acknowledgement}

This study was carried out with the support of the GSP Project No. 213007-05-5-SBM10, the Ministry of Agriculture, Food and Rural Affairs, Republic of Korea.

\section{Conflict of Interests}

The authors declare that there is no conflict of interests. 


\section{References}

Ellison AM, Buckley HL, Miller TE, Gotelli NJ (2004) Morphological variation in Sarracenia purpurea (Sarraceniaceae): geographic, environmental, and taxonomic correlates. Am J Bot. 91(11): 1930-1935

Badri M, Ilahi H, Huguet T, Aouani ME (2007). Quantitative and molecular genetic variation in sympatric populations of Medicago laciniata and M. truncatula (Fabaceae): relationships with ecogeographical geographical factors. Genet. Res. 89: 107-122

Badri M, Bouhaouel I, Arraouadi S, Tammalli W, Huguet T, Aouani ME (2016) Variation in tolerance among Tunisian populations of Medicago truncatula. Plant Genetic Resources: Characterization and Utilization, 14:41- 49

Burton GW and Devane EW (1953) Estimating heritability in tall fascue from replicated clonal material. Agron. J. 45:478-481

Chung MY, López-Pujol J, Chung JM, Kim KJ, Park SJ, and Chung MG (2015). Polyploidy in Lilium lancifolium: evidence of autotriploidy and no niche divergence between diploid and triploid cytotypes in their native ranges. Flora 213:57-68. doi: 10.1016/j.flora.2015.04.002

Chung T (1965) Illustrated encyclopedia of Fauna \& Flora of Korea. Vol. 5. Tracheophyta. Genus Chrysosplenium. Ministry of Education. Seoul. pp. 497-483

Criddle RS, Church JN, Smith BN, Hansen LD (2003) Fundamental Causes of the Global Patterns of Species Range and Richness 1. Russian Journal of Plant Physiology 50, 192-199

De Jong P (1974) Some notes on the evolution of lilies. Lily Yearbook, vol 27, pp. 23-28

Dhiman MR, Moudgil S, Prakash C, Kumar R, and Kumar S (2015) Biodiversity in Lilium: A Review. International Journal of Horticulture. 8(8):83-97

Du YP, He HB, Wang ZX, Wei C, Li S, Jia GX (2014) Investigation and evaluation of the genus Lilium resources native to China. Genet Resour Crop Evol 61:395-412

Eriksson O (1996) Regional dynamics of plants: a review of evidence for remnant, source-sink and metapopulations. Oikos 77:248- 258

Gao YD, Gao XF (2016) "Accommodating Nomocharis in Lilium (LIliaceae)," Phytotaxa. 277(2):205-210

Grasotti A, Gimelli F (2011) Bulb and cut flower production in the genus Lilium: current status and the future. Acta Hortic 900:21-42

Haw SG (1986) The lilies of China. B.T. Batsford Ltd., London Jeong JH, Kim KS, and Hong YP (1991). Distribution of Korean native lilies and environmental conditions of their native habitats. J. Kor. Soc. Hort. Sci. 32:270-277
Johnson HW, Robinson HF, Comstock RE (1955) Estimates of genetic and environmental variability in soybeans. Agronomy Journal. 47(7):314-318

Kim T (2008) Wild flowers and resources plants in Korea. 1-5, Seoul: SNU press

Kim YS, Lee WB (1990a) A study of morphological characters on the genus Lilium L. in Korea. Korean Journal of Plant Taxonomy. 20(3):165-178

Kim YS, Lee WB (1990b) A study of anatomical characters on the genus Lilium L. in Korea," Korean Journal of Plant Taxonomy, vol. 20(3):179-189

Lee C (2003) Coloured flora of Korea 1-2, Seoul: Hyangmunsa.

Lee SI, Nguyen TX, Kim JH, Kim NS (2019) Cytological variations and long terminal repeat (LTR) retrotransposon diversities among diploids and B-chromosome aneuploids in Lilium amabile Palibin. Genes \& genomics. 41(8):941-950

Lee T (1980) Illustrated flora of Korea. Hyangmunsa, Seoul.

Lighty RW (1969) The lilies of Korea. In: The lily yearbook, RHS, London. 31:31-39

Lim KB (2013) Korean species lilies (Lilium tsingtauense). Lilies and related plants. RHS. 87-92

Lucidos JGB, Kwang R, Younis A, Kim CK, Hwang YJ, Son BG and Lim KB (2013) Different day and night temperatures responses in Lilium hansonii in relation to growth and flower development. Hort Environ Biotech. 54:405-411

Matthews V (2007) The International Lily Register and Checklist. RHS London. 4th Edition

McRae E (1998) Lily species., In Lilies, Timber Press, Portland, Ore.USA, pp. 319-330

Morgan KK, Hicks J, Spitze K, Latta L, Pfrender ME, Weaver CS et al (2001). Patterns of genetic architecture for life-history traits and molecular markers in a subdivided species. Evolution 55:1753-1761

Nguyen TX, Kim BR, Park DR, Kim YK, Nguyen VY, Na JK, Kim NS, Kim JH (2019) Karyotype and B chromosome variation in Lilium amabile Palibin. Genes \& genomics. 41(6):647-655

Singh RK and Choudhary BD (1979), Biometrical methods in quantitative genetic analysis, New Delhi: Kalyani Publisher

Sivasubramanian S, Menon M (1973) Heterosis and inbreeding depression in rice. Madras Agric. J. 60(7):1139-1140

Song JT, Jeong HB, Kim BW, Jin HS (1989) The Sauras of Korean resourses plants, Seoul. Ilheung Co. pp. 512-513

Spitze K (1993) Population-Structure in Daphnia obtusa- Quantitative genetic and allozymic variation. Genetics, 135(2):367-374

Synge PM (1980) Lilies, London: B.T. Batsford

Van Tuyl JM, Arens P (2011) Lilium breeding history of the mordern cultivar assortment. Acta Horticult 900:223-230

Wilson EH (1925) The lilies of Eastern Asia. Dulau \& Co. Ltd, London. pp 110 